
\title{
S Research Square
}

\section{Generalized Joint Hypermobility among School- going children in Majmaah region, Saudi Arabia}

Mohamed Sherif Sirajudeen ( $\nabla$ m.sirajudeen@mu.edu.sa )

Majmaah University College of Applied Medical Sciences https://orcid.org/0000-0002-6934-5352

Mohamed Waly

Majmaah University College of Applied Medical Sciences

Mazen Alqahtani

Majmaah University College of Applied Medical Sciences

Msaad Alzhrani

Majmaah University College of Applied Medical Sciences

Hariraja Muthusamy

Majmaah University College of Applied Medical Sciences

Radhakrishnan Unnikrishnan

Majmaah University College of Applied Medical Sciences

Rashmi Saibannavar

Majmaah University College of Applied Medical Sciences

\section{Wafa Alrubaia}

Majmaah University College of Applied Medical Sciences

\section{Anandh Vaiyapuri}

Majmaah University College of Applied Medical Sciences

\section{Gopal S Nambi}

Prince Sattam bin Abdulaziz University College of Applied Medical Sciences

\section{Research article}

Keywords: Beighton score, Joint hypermobility, Ligamentous laxity, Prevalence, Children, Saudi Arabia

Posted Date: November 13th, 2019

DOI: https://doi.org/10.21203/rs.2.17255/v1

License: (9) This work is licensed under a Creative Commons Attribution 4.0 International License. Read Full License 


\section{Abstract}

Background Generalized Joint Hypermobility (GJH) is common among schoolchildren and usually benign. However, progressively may lead to joint pain and developmental delay. Identifying the GJH at the school-age would facilitate to monitor early changes and to plan for early rehabilitative intervention. Hence, we aimed to determine the prevalence, pattern, and factors associated with the GJH among school-going children in the Majmaah region, Saudi Arabia.

Methods The school children of both genders aged 8 to 14 years from the Majmaah region of Saudi Arabia participated in this cross-sectional study. The Beighton's score was used to assess the joint hypermobility. Personal characteristics like age, height, weight, Body mass index (BMI), and handedness was also collected. Descriptive statistics were produced for personal characteristics, the point prevalence of hypermobility, frequency of Beighton score distribution, and prevalence of $\mathrm{GJH}$. The association between specific factors and the presence of GJH was analyzed using Chi-square tests and logistic regression measures.

Results The occurrence of GJH as defined by Beighton cutoff score $\geq 4$ in the 303 participated primary school children was $15.2 \%$. The prevalence of GJH was high among females (16.8\%) compared to males (13.4\%), but this difference is not statistically significant. Younger male children (age 8 to 11 years) were 16.7 times more probable to develop hypermobility (adjusted OR 0.06 [95\% $\mathrm{Cl} 0.01-0.56]$ ) compared to older male children (age 12 to 14 years). No associations were observed among female children.

Conclusion The prevalence rate reported in this study among school-going children was in the lower range in comparison with the rates reported across the globe. Beighton score of $\geq 4$ was adequate for use in identifying GJH among children in Saudi Arabia.

\section{Background}

The increase in mobility of one or more joints compared to the normal flexibility range is referred to as Joint hypermobility [1]. Ligament laxity is the primary cause of joint hypermobility [2]. Ligament laxity and the resulting joint hypermobility are cardinal features of genetic disorders like Marfan syndrome, Ehlers Danlos syndrome, or Osteogenesis imperfecta. However, in most cases, joint hypermobility is observed as a confined phenomenon and is referred to as the Generalised Joint Hypermobility (GJH). Rarely, in the absence of any genetic disorders joint hypermobility is associated with features like arthralgia, back pain, dislocation/subluxation, soft tissue rheumatic disorders, marfanoid habitus, skin abnormalities, eye signs, Incompetence of lower limb vessel valves or hernia or prolapse of rectum and is termed as joint hypermobility syndrome [3].

The reported occurrence of GJH in children with the age group of 6-15 years varies between $8.8 \%$ [4] and $64.6 \%$ [5]. The prevalence of GJH is high in girls and declines as the age increases [6-10]. Jansson et al. in their study among Swedish school children reported that regardless of age, the girls had presented with marked joint hypermobility. However, the presentation of joint laxity in boys declines as the age progress, 
whereas in the girls, the joint laxity is at its maximum with the age of 15 years [11]. Earlier researchers demonstrated an influence of ethnic background on $\mathrm{GJH}$. There is a high prevalence of GJH among Asian and African populations compared to the Western population [12-15]. Nonetheless, literature is inadequate regarding the prevalence of GJH among children in the Gulf region.

Beighton score is a valid and reliable tool to screen the hypermobility of the joints and widely used across the globe $[16,17]$. Beighton's method includes assessment of hypermobility in 9 joints (bilateral thumbs, bilateral little fingers, bilateral elbows, bilateral knees, and the trunk). The score ranges from zero $(0)$ to nine (9); one (1) point has been awarded for the participant's ability to carry out each component of the test [12]. All the nine tests were easy to perform and provides quantitative data. The most recommended cutoff score for GJH was $\geq 4$ for GJH [3]. Juul et al. and Smits-Engelsman et al. recommended standard protocols to be administered in children $[16,17]$.

GJH is common among schoolchildren and usually benign. However, progressively may lead to joint pain and developmental delay. Identifying the GJH at the school-age would facilitate to monitor early changesand to plan for early rehabilitative intervention [5]. Hence this study first of its kind in Saudi Arabia is focused on exploring the prevalence of GJH and associated factors amidst school-going children in the Majmaah region.

\section{Methods}

\section{Study design, setting and participants}

The school children of both genders aged 8 to 14 years from the Majmaah region of Saudi Arabia participated in this cross-sectional study. Permission was obtained from the Information and Planning Authority for Education-Majmaah, under the Ministry of Education, Saudi Arabia. A letter containing the description of study design and seeking the cooperation of Headteachers of Schools was sent. Children with any apparent or reported signs of disabilities such as cognitive, developmental, or bodily as per the medical data available in school were not included in this study [1].

\section{Anthropometry measurements}

The data related to personal characteristics like age (in years), gender, height (in centimeters), and weight (in kilograms) were collected. Height in standing and weight have been measured by a standard gold method (bare feet, measured to the proximate $1 \mathrm{~cm}$ and $100 \mathrm{~g}$, respectively). BMI calculation was done with a metric formula, weight (in kg's) divided by height (in meters squared) and children were sorted as underweight (BMI less than 18.5), ideal weight (BMI range between 18.5-24.9), overweight (BMI range between 25-29.9) or obese (BMI greater than 30) as per the recommended criteria [18].

\section{Beighton score for Screening GJH}


The screening criteria comprises five (5) clinical test, and each of them was awarded either zero (0) or one (1) based on their attempt. These test scores are summed at the end, which will be ranging from zero (0) to nine (9).

- Researcher passively performs thumb apposition to the flexor side of the forearm and was performed on the right and left sides, the score of 1 is awarded if the whole thumb touches the flexor side of the forearm (900 of shoulder flexion with extended elbow and pronation of forearm);

- Researcher passively performs dorsiflexion of the 5th metacarpophalangeal joint on the right and left sides $\geq 900$ (sitting on chair, arm abducted to 800 , elbow flexed 900 , forearm rested on the table in pronation);

- Researcher passively performs hyperextension of the elbow joint on the right and left sides $\geq 100$ (The subjects were made to sit in a chair with shoulder positioned to 900 of flexion with forearm supinated);

- Researcher passively performs hyperextension of the knee on the right and left sides $\geq 100$ (The subjects were positioned in supine lying with legs supported on a table); and

- The subjects have been asked to perform flexion of the trunk, with knees in the extended position, so that the palms rest easily on the ground [16].

The cutoff score of $\geq 4$ was considered as GJH [3]. Also, a cutoff score $\geq$ of 6 was used to analyze any association. A $360^{\circ}$ universal goniometer was used to measure the joint angles. The measurements and Beighton maneuvers were performed by two Physical therapists with 15 years of experience in the area of Pediatric practice and research.

\section{Ethical consideration}

Approval was obtained from Majmaah University Ethical Committee (Approval. No. MURECOct21/COM-2018/6). Children's parents have been explained with the information (Oral / written) detailing the study, and they signed informed consent to permit their child to participate in the research. Moreover, assent was also obtained from the participating children before their enrollment in this research.

\section{Statistical analysis}

The data was recorded in the Microsoft Excel sheet and analyzed using SPSS (Version 17.0) for Windows. Descriptive statistics were produced for personal characteristics, the point prevalence of hypermobility, and frequency of Beighton score distribution. The prevalence of GJH was calculated by taking the number of children diagnosed for GJH (Beighton cutoff score of $\geq 4$ or $\geq 6$ ) and dividing it by the total number of students who participated in the study. Chi-square statistic was used to compute the association between binary variables and the presence/absence of $\mathrm{GJH}$. Trend analysis was done using 
logistic regression to find out the associations between categorical variables and the presence or absence of GJH. The level of probability of $5 \%$ was used to indicate statistical significance.

\section{Results}

A total of 303 children participated in this study. The details regarding the personal characteristics are presented in Table 1 . The majority of the participated children were females (53.1\%) compared to males $(46.9 \%)$. Nearly $69.3 \%$ of the children belonged to the $8-11$ age group. Concerning BMI, the majority of the children were underweight $(53.1 \%)$ whereas $34.7 \%, 7.9 \%$ and $4.3 \%$ of them were normal weight, overweight and obese respectively. Most of the participants were right-hand dominants (95.7\%).

The distribution of the total Beighton score of the participants is presented in Table 2. The majority of the participants (75.6\%) did not exhibit hypermobility in any of the joints tested in the Beighton score (Score0 ). None of the participants in this present study demonstrated hypermobility in all sites tested in the Beighton score. The occurrence of GJH as formulated by Beighton cutoff score $\geq 4$ in the 303 participated primary school children was $15.2 \%$ (Males-13.4\% and Females-16.8\%). When a more vigorous cutoff ( $\geq 6$ ) was used, the prevalence was $7.6 \%$ (Males $-4.5 \%$ and Females-9.9\%).

Table 3 represents the distribution of the participants' joint hypermobility. The occurrence of hypermobility is high in the elbows (17.2\%), then by the thumbs (12.5\%), little fingers (12.5\%), knees $(8.6 \%)$ and trunk $(0.7 \%)$. In females, hypermobility of thumb was more predominant than elbow, knee, finger and trunk hypermobility $(19.2 \%, 16.8 \%, 10.6 \%, 8.1 \%$, and $1.2 \%$ respectively). In males, hypermobility of the fingers was more predominant than elbow, knee, thumb and trunk hypermobility $(18.3 \%, 17.6 \%$, $6.3 \%, 4.9 \%$, and $0 \%$ respectively). The trunk hypermobility in males was unusual as none of the 142 males could place the palms together completely on the ground with knee in full extension.

The association between personal characteristics and GJH is summarized in Table 4. In males, the relationship between age and presence of GJH (cutoff of $\geq 4$ ) have shown a positive association, both with or without adjustment of other variables (BMI and hand dominance). Males aged 8 to 11 years were 16.7 times more probable for having hypermobility (adjusted OR 0.06 [95\% $\mathrm{Cl} 0.01-0.56]$ ) compared to males aged 12 to 14 years (Table 5). There were no other associations seen when cutoff of $\geq 4$ is used to define GJH in both sexes. No associations have been found with GJH for the variables assessed by using the cutoff of $\geq 6$ in both genders.

\section{Discussion}

This is the first study in the entire Gulf region, reflecting the Arab ethnicity to report the prevalence of GJH among school children aged 8 to 14 years. In the present study, the prevalence of GJH was $15.2 \%$, when using the cutoff score of greater than or equal to 4 hypermobile joints from the 9-point scoring system of Beighton. The prevalence reported in our study is comparable with the prevalence reported among children at Denmark (9.4\%), Egypt (16\%), United Kingdom (19.2\%) and less compared to rates reported 
from Iceland (27.7\%), Italy (35.4\%) and India (61.2\%) [3,19-23]. The prevalence of GJH was high among females $(16.8 \%)$ compared to males $(13.4 \%)$, but this difference is not statistically significant $(P<0.05)$. This finding is consistent with the rates reported by El-Garf et al. among Egyptian children (males - 14.4\% and females-18\%) [20]. Gyldenkerne et al. reported a statistically significant high occurrence of GJH among females (16.6\%) compared males (3\%) among Children in Denmark [19]. None of the earlier studies reported a high incidence of GJH among males compared to females [3,19-23].

Female children in our study predominantly presented with hypermobility at the thumb and elbow, whereas males were commonly presented with hypermobility at the fingers and elbows. It was fascinating that our participants have shown considerably less hypermobility with the joint of the lumbar spine. This may be better described by the factuality that the most of the range of flexion of the lumbar spine is a conjoint of extensibility of hamstrings and actual vertebral flexion [24], and short hamstrings would be one of the factors that are associated with reduced lumbar flexion in males [25]. Perhaps, a perceived reduction in flexion of the lumbar spine would have been caused by tight hamstrings and this, in turn, could be a reason for low occurrence of hypermobility of the lumbar spine among the boys in the present study.

In our study, the rate of hypermobility declined with an increase in age among males and not in females. The researches among Egyptian and Swedish children reported the inverse age-related decrease in the prevalence of GJH in both males and females $[11,20]$. The degree of collagen cross-linking is related to hypermobility of the joints as this is believed to increase the collagen ability to attract and hold water and thereby increases the mobility of the joints: as the age increases there is a decrease in body water content and increase in cross-linking of collagen molecules, this accounts for the decrease in joint hypermobility. Another factor that would reduce joint mobility at an older age is increased diameters of muscle fibers $[5,16]$. Beighton et al. states that the joint laxity is at its maximum at birth, then reduces more quickly during the span of childhood, less quickly in the span of adolescents and more slowly during the span of adulthood [26].

The presence of GJH was not associated with Body mass index (BMI) and Hand dominance both in males and females. Clinch et al. reported a positive association between $\mathrm{GJH}$ and BMI among females and not in males. Obese females were 2.7 times more prone to develop hypermobility compared to females who were underweight [3]. Contrastingly, a previous study from India reported an association between hypermobility and moderate and severe malnutrition [23]. No association was found among the variables assessed in GJH when laxity of the joint was scored using a cutoff of greater than or equal to 6 both in males and females. A previous study in the United Kingdom using Beighton score cutoff of greater than or equal to 6 compared with greater than or equal to 4 to measure generalized joint laxity, have reported that there is stronger evidence of associations between physical activity and maternal education. The authors also suggested raising the cutoff from $\geq 4$ to $\geq 6$ to determine GJH [3].

\section{Study limitations}


One of the limitations of the present study is that the clinical symptoms studied by previous researchers is not assessed [20-23,27]. The correlations between GJH and clinical symptoms are not clear. Al-Rawi et al. (a study over the university students aged between 20-24 years) have found a correlation between joint hypermobility and the symptoms/signs including joint complaints and ligamentous sprains [28]. A study conducted by Mikkelson and Qvindesland among 12-year old children have discussed that hypermobility is not associated with any kind of joint symptoms [21,29]. Grahame's study concludes that "it is not yet known whether there are a variety of hypermobilities (symptomatic or otherwise) that are not part of a connective tissue disorder" [30]. A further limitation of the present study is that parental or sibling hypermobility, which could be an added "risk" factor for hypermobility is not assessed. Like the limitations encountered in any other observational studies, we can neither rule out the confounding and chance nor establish causal or temporal relationship for the associations reported.

\section{Conclusion}

Using the criteria of standard cutoff of $\geq 4$ on Beighton score, 46 of the 303 school children $(15.2 \%)$ in our research was currently diagnosed as having GJH. The prevalence rate reported in this study among school-going children was in the lower range in comparison with the rates reported across the globe. This recommends that a Beighton score of $\geq 4$ is appropriate to identify children present with a pathologic entity. Raising the Beighton score to increase the threshold for diagnosis would end up in diagnosing only the tiny proportion of children in whom it is difficult to find out the risk factors and pathologic sequel.

Stronger evidence of associations was found in this study with the age of the male students when using the Beighton score cutoff of $\geq 4$ compared with $\geq 6$ to define generalized joint laxity. Finally, it is very important to formulate a new and specific tool for a thorough evaluation of laxity of the joint in the growing musculoskeletal system-which can be administered to distinguish children with risk factors such as pain and pathologies of connective tissues from minor cases, who don't require further medical attention.

\section{Abbreviations}

BMI: Body mass index; GJH: Generalized Joint Hypermobility.

\section{Declarations}

\section{Ethical approval and consent to participate}

Approval was obtained from Majmaah University Ethical Committee (Approval. No. MURECOct21/COM-2018/6). Children's parents have been explained with the information (Oral / written) detailing the study, and they signed informed consent to permit their child to participate in the research. Moreover, assent was also obtained from the participating children before their enrollment in this research. 


\section{Consent for publication}

Not applicable

\section{Availability of data and materials}

The datasets used and/or analysed during the current study are available from the corresponding author on reasonable request.

\section{Competing interests}

Nil

\section{Funding}

This research is funded by Deanship of Scientific Research at Majmaah University for supporting this work under Project Number No. 38/146.

\section{Author Contribution}

All authors contributed to literature review, concept and research design. MSS, MW, HM, RU, RS and WA performed data collection. MSS, MW and HM performed data analysis and drafting of manuscript. All the authors reviewed and approved the final manuscript. MSS would be the guarantor for this article.

\section{References}

1. Romeo DM, Lucibello S, Musto E, Brogna C, Ferrantini G, Velli C, Cota F, Ricci D, Mercuri E. Assessing joint hypermobility in preschool-aged children. The Journal of pediatrics. 2016;176:162-6.

2. Grahame R. Hypermobility-not a circus act. Int J Clin Pract. 2000; 54: 314-5

3. Clinch J, Deere K, Sayers A, Palmer S, Riddoch C, Tobias JH et al. Epidemiology of Generalized Joint Laxity (Hypermobility) in Fourteen-Year-Old Children From the UK: A Population-Based Evaluation. Arthritis and Rheumatism. 2011;63(9):2819-27.

4. Vougiouka O, Moustaki M, Tsanaktsi M. Benign hypermobility syndrome in Greek schoolchildren. Eur J Pediatr. 2000;159:628.

5. Lamari NM, Chueire AG, Cordeiro JA. Analysis of joint mobility patterns among preschool children. Sao Paulo Med J. 2005;123: 119-23.

6. Bulbena A, Duro JC, Porta M, Faus S, Vallescar R. Clinical assessment of hypermobility of joints: assembling criteria. J Rheumatol. 1992; 19: 115-22. 
7. Silman AJ, Day SJ, Haskard DO. Factors associated with joint mobility in an adolescent population. Ann Rheum Dis. 1987; 46:209-12.

8. Larsson LG, Baum J, Mudholkar GS. Hypermobility: features and differential incidence between the sexes. Arthritis Rheum. 1987; 30: 1426-30

9. Bird HA, Tribe CR, Bacon PA. Joint hypermobility leading to osteoarthrosis and chondrocalcinosis. Ann Rheum Dis. 1978; 37: 203-11

10. Hudson N, Starr MR, Esdaile JM, Fitzcharles MA. Diagnostic associations with hypermobility in rheumatology patients. Br J Rheumatol. 1995; 34: 1157-61

11. Jansson A, Saartok T, Werner S, Renström P. General joint laxity in 1845 Swedish school children of different ages: age- and gender-specific distributions. Acta Pædiatrica.2004; 93: 1202-6.

12. Beighton P, Solomon L, Soskolne CL. Articular mobility in an African population. Ann Rheum Dis. 1973; 32: 413-8

13. Carter C, Wilkinson J. Persistent joint laxity and congenital dislocation of the hip. J Bone Joint Surg Br. 1964; 46: 40-5

14. Jessee EF, Owen DS, Jr, Sagar KB. The benign hypermobile joint syndrome. Arthritis Rheum. 1980; 23: $1053-6$

15. Bird HA. Joint hypermobility in children. Rheumatology.2005; 44(6):703-4.

16. Smits-Engelsman B, Klerks M, Kirby A. Beighton score: a valid measure for generalized hypermobility in children. J Pediatr. 2011; 158(1): 119-23.

17. Juul B, Rogind H, Jensen DV, Remvig L. Inter-examiner reproducibility of tests and criteria for generalized joint hypermobility and benign joint hypermobility syndrome. Rheumatology 2007;46:1835-41.

18. Gerver WJM, de Bruin R. Paediatric morphometrics: A reference manual. $2^{\text {nd }}$ Maastricht, Germany: Universitaire Pers Maastricht; 2001.

19. Gyldenkerne B, Iversen K, Roegind H, Fastrup D, Hall K, Remvig L. Prevalence of general hypermobility in 12-13-year-old school children and impact of an intervention against injury and pain incidence. Advances in Physiotherapy. 2007;9(1):10-5

20. El-Garf AK, Mahmoud GA, Mahgoub EH. Hypermobility among Egyptian children: prevalence and features. The Journal of rheumatology. 1998;25(5):1003-5.

21. Qvindesland A, Jonsson H. Articular hypermobility in Icelandic 12-year-olds. Rheumatology. 1999;38(10):1014-6.

22. Leone V, Tornese G, Zerial M, Locatelli C, Ciambra R, Bensa M, Pocecco M. Joint hypermobility and its relationship to musculoskeletal pain in schoolchildren: a cross-sectional study. Archives of disease in childhood. 2009;94(8):627-32.

23. Hasija RP, Khubchandani RP, Shenoi S. Pediatric rheumatology-Joint hypermobility in Indian children. Clinical \& Experimental Rheumatology. 2008;26(1):146-50. 
24. Corben T, Lewis JS, Petty NJ. Contribution of lumbar spine and hip movements during the palms to floor test in individuals with diagnosed hypermobility syndrome. Physiother Theory Pract. 2008;24:1-12.

25. Gajdosik RL, Albert CR, Mitman JJ. Influence of hamstring length on the standing position and flexion range of motion of the pelvic angle, lumbar angle and thoracic angle. $J$ Orthop Sports Phys Ther. 1994;20:213-9.

26. Beighton P, Grahame R, Bird H. Hypermobility of joints. $3^{\text {rd }}$ London: Springer-Verlag; 1999.

27. Seçkin Ü, Tur BS, Yılmaz Ö, Yağcı İ, Bodur H, Arasıl T. The prevalence of joint hypermobility among high school students. Rheumatology international. 2005;25(4):260-3.

28. Al-Rawi ZS, Al-Aszawi AJ, Al-Chalabi T. Joint mobility among university students in Iraq. $\mathrm{Br} \mathrm{J}$ Rheumatol. 1985; 24: 326-31.

29. Mikkelsson M, Salminen JJ, Kautiainen $\mathrm{H}$. Joint hypermobility is not a contributing factor to musculoskeletal pain in pre-adolescents. J Rheumatol. 1996; 23: 1963-7.

30. Grahame R. Joint hypermobility and genetic collagen disorders: are they related? Arch Dis Child. 1999; 80: 188-91

\section{Tables}

Table 1 Personal Characteristics of Participated Children

\begin{tabular}{cc}
\hline Characteristics & Frequency (\%) / Mean (SD) \\
\hline Gender & $142(46.9)$ \\
Male & $161(53.1)$ \\
Female & $210(69.3)$ \\
Age (Years) & $93(30.7)$ \\
$8-11$ & $138.10(11.7)$ \\
$12-14$ & $37.90(12.1)$ \\
Height & \\
Weight & $161(53.1)$ \\
BMI & $105(34.7)$ \\
Under weight & $24(7.9)$ \\
Normal weight & $13(4.3)$ \\
Overweight & $13(4.3)$ \\
Obese & $290(95.7)$ \\
Hand Dominance & \\
Left & \\
Right &
\end{tabular}

SD - Standard Deviation, BMI - Body Mass Index 
Table 2 Frequency distribution of Total Beighton Score and Prevalence of Generalized Joint Hypermobility (Based on Cutoff $\geq 4$ or $\geq 6$ )

\begin{tabular}{cc}
\hline Score & Frequency (\%) \\
\hline $\boldsymbol{0}$ & $229(75.6)$ \\
1 & $5(1.7)$ \\
2 & $22(7.3)$ \\
\hline 3 & $1(0.3)$ \\
\hline $\mathbf{4}$ & $21(6.9)$ \\
\hline 5 & $2(0.7)$ \\
\hline 6 & $13(4.3)$ \\
\hline 7 & $1(0.3)$ \\
\hline $\boldsymbol{8}$ & $9(3)$ \\
\hline 9 & $0(0)$ \\
\hline Hypermobility & $46(15.2)$ \\
\hline Cutoff $\geq 4$ & $23(7.6)$ \\
\hline Cutoff $\geq 6$ &
\end{tabular}

Table 3 Point prevalence of Joint hypermobility at various sites used in the Beighton criteria

\begin{tabular}{|c|c|c|c|}
\hline Beighton Site & $\begin{array}{c}\text { Male } \\
(\mathrm{n}=142) \\
\text { Frequency (\%) }\end{array}$ & $\begin{array}{c}\text { Female } \\
(\mathrm{n}=161) \\
\text { Frequency }(\%)\end{array}$ & $\begin{array}{c}\text { All } \\
(\mathrm{n}=303) \\
\text { Frequency }(\%)\end{array}$ \\
\hline \multicolumn{4}{|l|}{ Finger } \\
\hline Left & $22(15.5)$ & $13(8.1)$ & 35 (11.5) \\
\hline Right & 26 (18.3) & $12(7.4)$ & 38 (12.5) \\
\hline \multicolumn{4}{|l|}{ Thump } \\
\hline Left & $7(4.9)$ & 31 (19.2) & 38 (12.5) \\
\hline Right & $7(4.9)$ & $29(18)$ & 36 (11.9) \\
\hline \multicolumn{4}{|l|}{ Elbow } \\
\hline Left & 25 (17.6) & 27 (16.8) & $52(17.2)$ \\
\hline Right & 25 (17.6) & 27 (16.8) & $52(17.2)$ \\
\hline \multicolumn{4}{|l|}{ Knee } \\
\hline Left & $9(6.3)$ & 17 (10.6) & $26(8.6)$ \\
\hline Right & $8(5.6)$ & 16 (9.9) & $24(7.9)$ \\
\hline Trunk & $0(0)$ & $2(1.2)$ & $2(0.7)$ \\
\hline
\end{tabular}

Table 4 Association between personal characteristics and presence of Generalized Joint Hypermobility (Based on Beighton Score $\geq 4$ or $\geq 6$ ) 


\begin{tabular}{|c|c|c|c|c|c|c|}
\hline \multirow[t]{2}{*}{ Characteristics } & \multicolumn{3}{|c|}{$\begin{array}{c}\text { Hypermobility } \\
\text { (Beighton score } \geq 4 \text { ) }\end{array}$} & \multicolumn{3}{|c|}{$\begin{array}{c}\text { Hypermobility } \\
\text { (Beighton score } \geq 6 \text { ) }\end{array}$} \\
\hline & Yes & No & Significance $\mathrm{P}^{\mathrm{a}}$ & Yes & No & Significance $\mathrm{P}^{\mathrm{a}}$ \\
\hline Gender & & & 0.411 & & & 0.100 \\
\hline \multicolumn{7}{|l|}{$(n=303)$} \\
\hline Male & 19 & 123 & & 7 & 135 & \\
\hline Female & 27 & 134 & & 16 & 145 & \\
\hline \multicolumn{7}{|l|}{ Males $(n=142)$} \\
\hline \multicolumn{7}{|l|}{ Age (Years) } \\
\hline From 8 to 11 & 18 & 76 & $0.005^{*}$ & 6 & 88 & 0.248 \\
\hline From 11 to 14 & 1 & 47 & & 1 & 47 & \\
\hline \multicolumn{7}{|l|}{$B M I$} \\
\hline Under weight & 11 & 70 & 0.368 & 3 & 78 & 0.262 \\
\hline Normal weight & 5 & 31 & & 2 & 34 & \\
\hline Over weight & 1 & 15 & & 1 & 15 & \\
\hline Obese & 2 & 7 & & 1 & 8 & \\
\hline \multicolumn{7}{|l|}{ Hand Dominance } \\
\hline Left & 2 & 9 & 0.745 & 1 & 10 & 0.455 \\
\hline Right & 17 & 114 & & 6 & 125 & \\
\hline \\
\hline \multirow{2}{*}{\multicolumn{7}{|c|}{$\begin{array}{c}(\mathrm{n}=161) \\
\text { Age (Years) }\end{array}$}} \\
\hline & & & & & & \\
\hline From 8 to 11 & 22 & 94 & 0.231 & 12 & 104 & 0.782 \\
\hline From 11 to 14 & 5 & 40 & & 4 & 41 & \\
\hline \multicolumn{7}{|l|}{$B M I$} \\
\hline Under weight & 16 & 63 & 0.247 & 10 & 69 & 0.347 \\
\hline Normal weight & 9 & 57 & & 4 & 62 & \\
\hline Over weight & 1 & 9 & & 1 & 9 & \\
\hline Obese & 1 & 5 & & 1 & 5 & \\
\hline \multicolumn{7}{|l|}{ Hand Dominance } \\
\hline Left & 1 & 3 & 0.433 & 1 & 3 & 0.561 \\
\hline Right & 26 & 131 & & 15 & 142 & \\
\hline
\end{tabular}

Table 5 Odd ratios for Association between personal characteristics and presence of Generalized Joint Hypermobility (Based on Beighton Score $\geq 4$ or $\geq 6$ ) 


\begin{tabular}{|c|c|c|c|c|}
\hline \multirow[t]{2}{*}{ Characteristics } & \multicolumn{2}{|c|}{$\begin{array}{c}\text { Hypermobility } \\
\text { (Beighton score } \geq 4 \text { ) }\end{array}$} & \multicolumn{2}{|c|}{$\begin{array}{c}\text { Hypermobility } \\
\text { (Beighton score } \geq 6 \text { ) }\end{array}$} \\
\hline & $\begin{array}{c}\text { Unadjusted OR } \\
(95 \% \mathrm{CI})\end{array}$ & $\begin{array}{c}\text { Adjusted OR } \\
(95 \% \mathrm{CI})\end{array}$ & $\begin{array}{c}\text { Unadjusted OR } \\
(95 \% \mathrm{CI})\end{array}$ & $\begin{array}{l}\text { Adjusted } \mathrm{OR}^{\beta} \\
(95 \% \mathrm{CI})\end{array}$ \\
\hline \multicolumn{5}{|l|}{ Gender } \\
\hline Male & $1.0($ Ref) & $1.0($ Ref $)$ & 1.0 (Ref) & 1.0 (Ref) \\
\hline Female & $1.0304(0.69-2.46)$ & $1.305(0.67-2.54)$ & $2.12(0.85-5.33)$ & $2.47(0.95-6.45)$ \\
\hline \multicolumn{5}{|l|}{ Males ( $n=142)$} \\
\hline \multicolumn{5}{|l|}{ Age (Years) } \\
\hline From 8 to 11 & $1.0($ Ref $)$ & 1.0 (Ref) & $1.0($ Ref $)$ & 1.0 (Ref) \\
\hline From 11 to 14 & $\begin{array}{c}0.09(0.012-0.695)^{*} \\
\text { P-value }(0.020)\end{array}$ & $\begin{array}{c}0.06(0.01-0.56)^{*} \\
\text { P-value }(0.013)\end{array}$ & $0.312(0.036-2.66)$ & $0.208(0.02-2.06)$ \\
\hline \multicolumn{5}{|l|}{$B M I$} \\
\hline Under weight & $1.0(\operatorname{Ref})$ & 1.0 (Ref) & $1.0($ Ref) & $1.0($ Ref $)$ \\
\hline Normal weight & $1.026(0.329-3.20)$ & $1.23(0.38-4.05)$ & $1.52(0.24-9.57)$ & $1.723(0.27-11.03)$ \\
\hline Overweight & $0.424(0.051-3.54)$ & $0.5(0.06-4.45)$ & $1.73(0.17-17.80)$ & $1.906(0.17-21.04)$ \\
\hline Obese & $1.82(0.33-9.90)$ & $5.23(0.66-41.17)$ & $3.24(0.30-35.02)$ & $5.757(0.45-73.63)$ \\
\hline \multicolumn{5}{|l|}{ Hand Dominance } \\
\hline Left & $1.0(\operatorname{Ref})$ & $1.0($ Ref) & $1.0(\operatorname{Ref})$ & $1.0(\operatorname{Ref})$ \\
\hline Right & $0.671(0.134-3.372)$ & $0.47(0.08-2.69)$ & $0.48(0.053-4.388)$ & $0.444(0.04-4.41)$ \\
\hline \multicolumn{5}{|l|}{$\begin{array}{l}\text { Females } \\
(n=161)\end{array}$} \\
\hline \multicolumn{5}{|l|}{ Age (Years) } \\
\hline From 8 to 11 & $1.0(\operatorname{Ref})$ & 1.0 (Ref) & $1.0($ Ref) & 1.0 (Ref) \\
\hline $\begin{array}{l}\text { From } 11 \text { to } 14 \\
\text { BMI }\end{array}$ & $0.534(0.189-1.51)$ & $0.58(0.2-1.73)$ & $0.84(0.25-2.7)$ & $0.89(0.25-3.14)$ \\
\hline Under weight & 1.0 (Ref) & $1.0($ Ref $)$ & $1.0(\operatorname{Ref})$ & $1.0($ Ref $)$ \\
\hline Normal weight & $0.621(0.25-1.51)$ & $0.66(0.27-1.63)$ & $0.445(0.132-1.49)$ & $0.43(0.13-1.49)$ \\
\hline Over weight & $0.43(0.051-3.71)$ & $0.5(0.05-4.8)$ & $0.76(0.08-6.71)$ & $0.66(0.07-6.74)$ \\
\hline Obese & $0.78(0.085-7.22)$ & $0.94(0.1-8.92)$ & $1.38(0.145-13.055)$ & $1.47(0.15-14.49)$ \\
\hline \multicolumn{5}{|l|}{ Hand Dominance } \\
\hline Left & 1.0 (Ref) & $1.0($ Ref $)$ & $1.0(\operatorname{Ref})$ & 1.0 (Ref) \\
\hline Right & $0.6(0.05-5.9)$ & $0.43(0.04-4.63)$ & $0.316(0.031-3.24)$ & $0.25(0.02-2.82)$ \\
\hline
\end{tabular}

OR - Odd Ratio, $\boldsymbol{\beta}$ - Adjusted for all other variables listed, CI - Confidence Interval, BMI - Body Mass Index,

* Significant $\mathrm{P}<0.05$

\section{Supplementary Files}

This is a list of supplementary files associated with this preprint. Click to download.

- TITLEPAGE.docx 